УДК 37.0

\title{
ИННОВАЦИОННЫЕ РЕСУРСЫ ЛИЧНОСТНОГО РАЗВИТИЯ ОБУЧАЮЩИХСЯ
}

Ищенко Наталья Васильевна ст. преподаватель Косовских Светлана Викторовна к.ф.-м.н., доцент Филонова Людмила Николаевна К.П.Н. ФГБОУ ВО «Курганский государственный университет»

Аннотация: Статья посвящена обзору и классификации электронных образовательных ресурсов в соответствии с их назначением, способствующих организации учебного процесса так, чтобы обучение проходило интересно, доступно и в комфортных условиях. Авторами предложено создание курса «Эдьютейнмент в образовании» для студентов педагогического направления подготовки и дополнительной образовательной программы повышения квалификации педагогов.

Ключевые слова: инновационные образовательные ресурсы, личностное развитие, эдьютейнмент.

\section{INNOVATIVE RESOURCES PERSONAL DEVELOPMENT OF STUDENTS}

\section{Ischenko Natalia Vasilyevna Kosovskikh Svetlana Viktorovna Filonova Ludmila Nikolaevna}

\begin{abstract}
The article is devoted to the review and classification of electronic educational resources in accordance with their purpose, contributing to the organization of the educational process so that learning is interesting, accessible and comfortable. The authors proposed the creation of the course "education In education" for students of the pedagogical direction of training and an additional educational program for advanced training of teachers.
\end{abstract}

Key words: innovative educational resources, personal development, edutainment. 
В современных условиях развития экономики знаний актуальной является подготовка компетентных специалистов, способных к творческому саморазвитию. Школа, ставя целью подготовку современного образованного человека, должна сегодня направлять образовательный процесс на формирование его как творчески активной, психологически устойчивой личности, и способной постоянно повышать уровень своей квалификации, умеющей принимать решения. Такой уровень личностной и профессиональной зрелости может сформироваться у человека, прежде всего, в результате целенаправленного саморазвития, что предопределяет особую роль личностного развития обучающихся.

Личностью в подчеркнуто специфическом смысле этого слова, является человек, у которого есть своя позиция, свое ярко выраженное сознательное отношение к жизни, мировоззрение, к которому он пришел в результате большой сознательной работы [1].

Личностное развитие обучающихся можно определить как поступательный, направленный процесс приобретения учащимися интеллектуальных, психологических и социальных компетенций за счет освоения знаний, умений и способностей, необходимых для осуществления учебной и дальнейшей профессиональной деятельности.

Для реализации личностного развития обучающегося необходимо задействовать все возможные ресурсы современного образования, в том числе инновационные. К таким ресурсам, по нашему мнению, относится образовательная технология, получившая в педагогической литературе название - эдьютейнмент.

Эдьютейнмент - это не что иное, как образование через игру или с элементами развлечения, то есть это явление, суть которого в том, что обучение должно быть интересным, развлекательным. В широком смысле эдьютейнмент - это любое знание, которое завернуто в «яркую обертку», а оттого - и в этом вопросе единодушны и педагоги, и психологи - усваивается быстрее, легче, лучше. Можно считать, что девизом этой образовательной технологии является: учёба - это радость познания. Истоки такого подхода к обучению можно найти еще в работах В.А. Сухомлинского, который считал, что игра это искра, зажигающая огонек пытливости и любознательности.

О.Л. Гнатюк в учебном пособии «Основы теории коммуникации» определяет эдьютейнмент как «цифровой контент, соединяющий образовательные и развлекательные элементы и обеспечивающий при этом 


\section{СОВРЕМЕННАЯ НАУКА И ЕЕ РЕСУРСНОЕ ОБЕСПЕЧЕНИЕ: ИННОВАЦИОННАЯ ПАРАДИГМА}

информирование аудитории при максимально облегчённом анализе событий» $[2$, c. 65$]$.

Н.А. Кобзева дает такое определение: «Эдьютейнмент - это технология обучения, рассматриваемая как совокупность современных технических и дидактических средств обучения, которая основана на концепции обучения через развлечение, смысл которой заключается в том, что знания должны передаваться в понятной, простой и интересной форме, а также в комфортных условиях» [3, с. 194].

Таким образом, являясь относительно новым термином в педагогике, эдьютейнмент способствует формированию первичного интереса к предмету с получением удовольствия от процесса обучения.

Данная технологии обучения основана на реализации следующих принципов:

1. Обучение с увлечением - формирование непосредственного интереса обучающегося, который приводит к развитию новых навыков и накоплению знаний.

2. Обучение с развлечением - развлечение выступает основным мотивом, который приводит к удовольствию, одновременно формируя стойкий интерес к процессу обучения, снимая психологическую нагрузку от процесса образования.

3. Принцип игры: благодаря универсальности игры происходит эффективный процесс обучения вне зависимости от возраста.

4. Принцип актуальности - использование актуальных возможностей современных технологий, таких как видео- и аудиоматериалы, дидактические игры, образовательные программы в мультимедийном формате и многие другие средства, при этом достигается максимальная вовлеченность обучающихся в образовательный процесс.

Средства эдьютейнмента для образования можно разделить на традиционные и современные. К традиционным средствам относятся книги, музыка, фильмы, образовательные игры, телепрограммы, радиопрограммы и свободные лекции. Современные средства делятся на электронные системы (электронные учебники, сетевые варианты музейных выставок), персональные компьютерные системы (компьютерные или видеоигры, электронные тренажеры, электронные энциклопедии) и веб-технологии (электронная почта, веб-квесты, вики, блоги, чаты, видеоконференции).

Актуальность данного вопроса привела к необходимости разработки образовательного курса «Эдьютейнмент в образовании», который планируется 
реализовывать в качестве элективного курса для студентов педагогического направления, а также в качестве дополнительной образовательной программы повышения квалификации педагогов.

Целью данного курса является повышение качества знаний студентов и педагогов в области эдъютейнмента - как технологии, обеспечивающей интенсификацию обучения и активизацию учебно-познавательной деятельности обучающихся. Основу могут составлять электронные образовательные ресурсы. Классификация электронных образовательных ресурсов по назначению, представлена в таблице 1 .

Таблица 1

\section{Электронные образовательные ресурсы}

\begin{tabular}{|c|c|c|c|}
\hline $\begin{array}{c}\text { № } \\
\text { П/ח }\end{array}$ & $\begin{array}{l}\text { Название } \\
\text { ресурса }\end{array}$ & Адрес ресурса & Краткая характеристика \\
\hline 1 & Kahoot! & https://getkahoot.com & \multirow{8}{*}{$\begin{array}{l}\text { Ресурсы, позволяющие создавать } \\
\text { викторины, обратную связь, чаты, } \\
\text { интерактивные доски для совместной } \\
\text { работы в реальном времени, а также } \\
\text { использовать анимацию, звук, } \\
\text { комментарии. }\end{array}$} \\
\hline 2 & Quizizz & https://quizizz.com & \\
\hline 3 & Triventy & http://www.triventy.com & \\
\hline 4 & Flippity & https://www.flippity.net & \\
\hline 5 & Plickers & https://get.plickers.com & \\
\hline 6 & Mentimeter & https://www.mentimeter.com & \\
\hline 7 & Classtime & https://www.classtime.com & \\
\hline 8 & Sli.do & https://www.sli.do & \\
\hline 9 & Easel.ly & http://www.easel.ly & \multirow{3}{*}{$\begin{array}{l}\text { Сервисы для создания и публикации } \\
\text { инфографики, красивого дизайна } \\
\text { визиток, презентаций, аватарки, заставок } \\
\text { для видео, иллюстраций в блог, плаката, } \\
\text { книги и так далее. }\end{array}$} \\
\hline 10 & Infogr & https://infogr.am & \\
\hline 11 & Canva & https://www.canva.com & \\
\hline 12 & $\begin{array}{l}\text { Screencast-O- } \\
\text { Matic }\end{array}$ & https://screencast-o-matic.com & \multirow{3}{*}{$\begin{array}{l}\text { Ресурсы, которые позволяют создавать } \\
\text { скринкасты (видео с экрана монитора), } \\
\text { видео посредством веб-камеры или } \\
\text { записывать экран и изображение с веб- } \\
\text { камеры одновременно, редактировать } \\
\text { фото и видео. }\end{array}$} \\
\hline 13 & $\begin{array}{l}\text { Movavi Screen } \\
\text { recorder }\end{array}$ & $\begin{array}{l}\text { https://softcatalog.info/ru/programmy/mov } \\
\text { avi-screen-capture }\end{array}$ & \\
\hline 14 & Edpuzle & https://edpuzzle.com/ & \\
\hline 15 & Toondoo & http://www.toondoo.com/ & \multirow[b]{2}{*}{$\begin{array}{l}\text { Сервисы для создания комиксов и } \\
\text { забавных электронных анимированных } \\
\text { открыток. } \\
\text { Готовый продукт можно скачать, } \\
\text { распечатать или опубликовать его в } \\
\text { социальных сетях. }\end{array}$} \\
\hline 16 & JibJab & https://www.jibjab.com/ & \\
\hline 17 & Math Fight & $\begin{array}{l}\text { https://app.rx24.ru/app/860529378/math- } \\
\text { fight-multiplayer-gam }\end{array}$ & \multirow{4}{*}{$\begin{array}{l}\text { Приложения для проведения } \\
\text { математических дуэлей, построения } \\
\text { различных типов графиков, создавания } \\
\text { таблиц, графического решения систем } \\
\text { уравнений, неравенств, разработке } \\
\text { интерактивных заданий по математике, } \\
\text { созданию рядов последовательных } \\
\text { учебных заданий, которые вовлекают } \\
\text { ученика в игру. }\end{array}$} \\
\hline 18 & $\begin{array}{l}\text { Desmos } \\
\text { калькулятор }\end{array}$ & https://www.desmos.com/ & \\
\hline 19 & $\begin{array}{l}\text { Desmos } \\
\text { Classroom } \\
\text { Activities }\end{array}$ & https://teacher.desmos.com/?lang=ru & \\
\hline 20 & Matific & https://www.matific.com/rus/ru/home/ & \\
\hline
\end{tabular}


Таким образом, преимущество использования инновационных образовательных ресурсов в реализации курса «Эдьютейнмент в образовании» заключается в том, что знания передаются в простой, понятной, доступной и увлекательной форме. С помощью данной технологии, сложно получить фундаментальные знания по новой профессии, но можно стать более эрудированным, получить новые или закрепить уже имеющиеся знания, развить умения и навыки по многим направлениям.

\section{Список литературы}

1. Рубинштейн С.Л. Основы общей психологии - Электронная библиотека психологии / URL: https://www.gumer.info/bibliotek_Buks/Psihol/rubin/intro.php (дата обращения 20.12.2020).

2. Гнатюк О.Л. Основы теории коммуникации. - М. : КНОРУС, 2010. $256 \mathrm{c}$.

3. Кобзева Н.A. Edutainment как современная технология обучения // Ярославский педагогический вестник. - 2012. - № 4 (II) (Психологопедагогические науки). С. 192 - 195. 